\title{
Combined effect of modified titanium carbide (TiC) particles and ethylene alpha olefins (POE) on properties of ethylene propylene diene monomer (EPDM)/TiC/POE composites for electronic application
}

\author{
Su, Jun; Li, Caihong
}

Published in:

Journal of Materials Science: Materials in Electronics

Link to article, DOI:

$10.1007 / \mathrm{s} 10854-019-00708-3$

Publication date:

2019

Document Version

Peer reviewed version

Link back to DTU Orbit

Citation (APA):

Su, J., \& Li, C. (2019). Combined effect of modified titanium carbide (TiC) particles and ethylene alpha olefins (POE) on properties of ethylene propylene diene monomer (EPDM)/TiC/POE composites for electronic application. Journal of Materials Science: Materials in Electronics, 30(4), 4164-4173. https://doi.org/10.1007/s10854-019-00708-3

\section{General rights}

Copyright and moral rights for the publications made accessible in the public portal are retained by the authors and/or other copyright owners and it is a condition of accessing publications that users recognise and abide by the legal requirements associated with these rights.

- Users may download and print one copy of any publication from the public portal for the purpose of private study or research.

- You may not further distribute the material or use it for any profit-making activity or commercial gain

- You may freely distribute the URL identifying the publication in the public portal 


\title{
Combined effect of modified Titanium carbide ( $\mathrm{TiC}$ ) particles and ethylene alpha olefins (POE) on properties of ethylene propylene diene monomer (EPDM)/TiC/POE composites for electronic application
}

\section{Jun $\mathrm{Su}^{1,2, *}$ and Caihong $\mathbf{L i}^{1}$}

1 College of Mechanics Engineering, Nanjing Institute of Industry Technology, Nanjing, 210023, People's Republic of China

2 Danish Polymer Centre, Department of Chemical and Biochemical Engineering, Technical University of Denmark, Søltofts Plads Building 227, 2800 Kgs. Lyngby, Denmark.

*Corresponding author: Jun Su; E-mail: aw_su@hotmail.com

\begin{abstract}
For the field of flexible electronic materials, titanium carbide (TiC) is still a new member that needs to be further investigated. In this study, the effects of surface modification, TiC content and ethylene alpha olefins (POE) amount on dielectric properties of ethylene propylene diene copolymer (EPDM) are investigated in detail. The addition of $20 \%$ modified $\mathrm{TiC}$ particles can improve the dielectric constant of EPDM control from 2.4 to 8.7 (360\% increase) at $10^{5} \mathrm{~Hz}$. However, the complex viscosity of EPDM control increases by 6.4 times at $1.7 \mathrm{~Hz}$ and the volume resistivity decreases by 3 order of magnitude. Moreover, the thermal conductivity of EPDM control only increase by $17 \%$. By comparison, the $20 \%$ POE not only increases the dielectric constant of EPDM/TiC (10/2) from 8.7 to 13.5 (55\% increase) at $10^{5} \mathrm{~Hz}$, with slight decrease of volume resistivity, but also decreases the complex viscosity of EPDM/TiC (10/2) from $119000 \mathrm{~Pa} \cdot \mathrm{S}$ to $57800 \mathrm{~Pa} \cdot \mathrm{S}(51 \%$ decrease) at $1.7 \mathrm{~Hz}$. Meanwhile, the addition of $20 \%$ POE can further enhance the thermal conductivity of EPDM/TiC (10/2) from $0.281 \mathrm{~W} /(\mathrm{m} \cdot \mathrm{K})$ to $0.416 \mathrm{~W} /(\mathrm{m} \cdot \mathrm{K})(48 \%$ increase $)$.
\end{abstract}


Keywords: Ethylene-propylene-diene, titanium carbide, thermal conductivity, volume resistivity, complex viscosity, dielectric and mechanical property

\section{Introduction}

Dielectric polymer/ceramic composites have attracted increasing attention in electronic domain worldwide ${ }^{[1-3]}$ Some multilayer capacitors and embedded sensors, which is made out of fluoride polymer/ceramic composites, possess high dielectric constant, due to the polar structure of fluoride polymer. However, the polar and rigid matrix can decrease the processing fluidity and increase the stiffness of fluoride polymer/ceramic composites, which restricts their application. ${ }^{[4-5]}$ With the development of flexible electronic wearable devices, there is an increased demand for flexible capacitors and flexible sensors. ${ }^{[6-7]}$

Ethylene propylene diene monomer (EPDM) is a random copolymer synthesized by ethylene, propylene and 5-ethylidene-2-norbornene. The non-polar and saturated backbone endows EPDM with good heat-resistance and low dielectric loss factor, making it suitable for matrix of long-term used electronic composites. ${ }^{[8-9]}$ But EPDM is a kind of non-self reinforced elastomers and exhibits low dielectric constant. ${ }^{[10]}$

The commonly used method to improve the dielectric constant of elastomers is the addition of fillers with high dielectric constant, such as ceramic powders, metal particles, carbon black, ionic conductors and so on ${ }^{[11-14]}$ The unique structure endows ceramic titanium carbide (TiC) with high dielectric constant. But TiC is brittle and has high dielectric loss factor. Thus, it is interesting to see whether the incorporation of TiC into EPDM can overcome their individual drawbacks and then obtain a composite with high tensile strength, high dielectric constant and low dielectric loss factor.

According to literatures, the inorganic fillers tend to aggregate in polymer matrix. 
The application of coupling agents can reduce such aggregation and improve the properties of polymer/filler composites. ${ }^{[8,15-16]}$ In this study, TiC particles are firstly surface modified by coupling agent isopropyl trioleic titanate (NDZ105) to reduce the agglomeration of TiC particles in EPDM matrix.$^{[17-18]}$ Then, different amount of TiC particles is added into EPDM matrix to investigate the effect of modified TiC on the bound rubber content, cure, crosslink density, rheological, mechanical and dialectical properties of EPDM/TiC composites. ${ }^{[19-21]}$

However, high amount of ceramic fillers can result in the sharply decreased processing fluidity and drastically increased electrical conductivity. In addition, the electronic devices can generate heat during daily usage, so the thermal conductivity of EPDM/TiC needs to be improved. ${ }^{[22-23]}$

Thereby, semi-crystal POE is selected to be added into EPDM/TiC. Compared to other semi-crystal resins, POE not only has crystal lattices, but also exhibits elasticity. The aim is to evaluate how the POE affect processing fluidity, electrical conductivity and thermal conductivity of EPDM/TiC composites. The effect of POE on dielectric and mechanical properties of EPDM/TiC is also investigated.

\section{Experimental}

\subsection{Materials}

The ethylene-propylene-diene monomer (EPDM J-4045) purchased by Jilin Petrochem., was used in this study. Ethylene alpha olefins (POE0203) was supplied by ExxonMobil Chemical, America. Compounding ingredients, such as dicumyl peroxide (DCP), zinc oxide, stearic acid, 2-Mercapto benzimidazole (MB) and polymerized 2, 2, 4-trimethyl-1, 2-dihydroquinoline (RD) are of reagent grade. TiC particles (density $4.93 \mathrm{~g} / \mathrm{cm}^{3}$ ) were purchased from Pengcheng Co., Ltd in Zibo, 


\begin{abstract}
Shandong province. The coupling agent isopropyl trioleic titanate (NDZ105) was purchased from Nanjing Shuguang chemical plant. The chemical/commercial name and structure of NDZ105 were listed in Table 1:
\end{abstract}

(Table 1)

\title{
2.2 Sample preparation
}

\subsubsection{Surface modification of TiC}

In this work, NDZ105 was used to modify the surface of the TiC particles. Firstly, $10 \mathrm{~g}$ pre-dried $\mathrm{TiC}$ powder was dispersed in $200 \mathrm{ml}$ isobutanol and was ultrasonically dispersed for $30 \mathrm{~min}$. Secondly, $0.1 \mathrm{~g}$ NDZ105 was added into the obtained liquid under nitrogen atmosphere. Thirdly, the reaction was taken place for $4 \mathrm{~h}$ at $80{ }^{\circ} \mathrm{C}$. Then, the TiC grafted with NDZ105 particles were dried in a vacuum oven at $60{ }^{\circ} \mathrm{C}$ for $72 \mathrm{~h}$ and then ground into powder. ${ }^{[24]}$

\subsubsection{Compounding of EPDM/TiC mixes}

According to ISO2393, EPDM, TiC and cure ingredients were mixed by a two roll mixing mill (Shanghai Rubber Machinery Works, China). EPDM and POE were blended above the melting temperature of $\operatorname{POE}\left(100^{\circ} \mathrm{C}\right)$, and then mixed with modified and unmodified TiC particles. The formulation of EPDM composites was listed in Table 2. Mixes were vulcanized in an electrically heated press at $170^{\circ} \mathrm{C}$ and 10.0 MPa for $15 \mathrm{~min}$.

(Table 2)

\subsection{Testing procedures}




\subsubsection{Fourier Transform Infrared Spectroscopy}

Fourier Transform Infrared Spectroscopy (FT-IR) spectra of NDZ105, unmodified and modified $\mathrm{TiC}$ particles after treatment were tested with a resolution of $4 \mathrm{~cm}^{-1}$ in the range of $400 \sim 4000 \mathrm{~cm}^{-1}$ by Nicolet NEXUS 670 spectrometer.

\subsubsection{Rheological measurement}

Rheological properties of EPDM control, EPDM/TiC and EPDM/TiC/POE0203 blends were tested by Anton Paar Rheo-Stress MCR302 instrument. The testing temperature is $100^{\circ} \mathrm{C}$.

\subsubsection{Cure properties}

Curing properties of EPDM control, EPDM/TiC and EPDM/TiC/POE0203 blends were tested by MDR 2000 Rheometer, purchased from Wuxi Liyuan Electronic \& Chemical Equipment Co., Ltd.. The test temperature and frequency is $170^{\circ} \mathrm{C}$ and $1.7 \mathrm{~Hz}$, respectively.

\subsubsection{Crosslink density measurement and bound rubber content}

Crosslink density of EPDM composites were tested by the solvent swell method and calculated by Flory-Rehner equation (1).

$$
v=-\frac{1}{V}\left[\frac{\ln \left(1-V_{R}\right)+V_{R}+\mu V_{R}^{2}}{V_{R}{ }^{1 / 3}-\frac{V_{R}}{2}}\right]
$$

Where $\mu, \mathrm{v}, \mathrm{V}_{\mathrm{R}}$ and $\mathrm{V}$ are the interaction parameter between toluene and elastomer, crosslink density of EPDM, volume fraction of EPDM after immersion and molar volume of toluene, respectively. ${ }^{[22]}$

The bound rubber content was calculated according to the equation (2): ${ }^{[24]}$

$$
\mathrm{R}_{\mathrm{b}}(\%)=100 \times\left[\mathrm{W}_{\mathrm{fg}}-\mathrm{W}_{\mathrm{t}}\left[\mathrm{m}_{\mathrm{f}} /\left(\mathrm{m}_{\mathrm{f}}+\mathrm{m}_{\mathrm{r}}\right)\right]\right] / \mathrm{W}_{\mathrm{t}}\left[\mathrm{m}_{\mathrm{r}} /\left(\mathrm{m}_{\mathrm{f}}+\mathrm{m}_{\mathrm{r}}\right)\right]
$$


Where $\mathrm{R}_{\mathrm{b}}, \mathrm{W}_{\mathrm{fg}}, \mathrm{W}_{\mathrm{t}}, \mathrm{m}_{\mathrm{f}}$ and $\mathrm{m}_{\mathrm{r}}$ are bound rubber content of EPDM gums, total weight of TiC and gel, weight of samples, fraction of TiC in the EPDM gums, fraction of EPDM in the EPDM gums, respectively.

\subsubsection{Scanning electron microscopy (SEM)}

The images of TiC dispersed in EPDM were observed by JSM-5900 scanning electron microscope.

\subsubsection{Mechanical properties}

The mechanical tests were carried out according to ISO 7619-1 using a CMT 5254 type electromechanical universal testing machine.

\subsubsection{Dielectric constant and dielectric loss factor of EPDM/TiC composites}

The dielectric constant and dielectric loss factor of EPDM/TiC composites were measured by Agilent 4294A precision impedance analyzer.

\subsubsection{Volume and surface resistivity}

According to IEC 60093, the volume and surface resistivity of EPDM composites were tested by a high-insulation resistance meter, purchased by Shanghai Precision \& Scientific Instrument Co., Ltd, China.

\subsubsection{Differential scanning calorimetry (DSC) measurement}

According to literature, the enthalpy of fusion of EPDM/TiC and EPDM/TiC/POE0203 were tested by DSC instrument Q200, supplied by TA. In order to prevent oxidative degradation of EPDM/TiC samples during the heating, the flux of $50 \mathrm{~mL} / \mathrm{min}$ argon purge gas was used. EPDM/TiC/POE samples are firstly heated from $20^{\circ} \mathrm{C}$ to $180^{\circ} \mathrm{C}$ at $30^{\circ} \mathrm{C} / \mathrm{min}$, and the temperature is held at $180^{\circ} \mathrm{C}$ for $5 \mathrm{~min}$ to eliminate the thermal history of samples during fabrication. Then, the 
EPDM/TiC/POE samples are cooled from $180^{\circ} \mathrm{C}$ to $20^{\circ} \mathrm{C}$ at $5{ }^{\circ} \mathrm{C} / \mathrm{min}$. Finally, the samples are heated from $20^{\circ} \mathrm{C}$ to $180^{\circ} \mathrm{C}$ at $5^{\circ} \mathrm{C} / \mathrm{min}$. The relative crystallinity (Xc) of samples were calculated according to equation (3): ${ }^{[17]}$

$$
X_{c}=\frac{\Delta H}{\Phi \times \Delta H^{*}} \times 100 \%
$$

Where $\Delta \mathrm{H}^{*}, \Delta \mathrm{H}$ and $\varphi$ are the fusion enthalpy of the perfect POE crystals, the fusion enthalpy of POE in EPDM/TiC/POE composites and the weight fraction of POE in EPDM/TiC/POE, respectively. The $\Delta \mathrm{H}^{*}$ of POE is $277.1 \mathrm{~J} / \mathrm{g}$.

\subsubsection{Thermal Conductivity of EPDM Composites}

According to ISO 8302, the thermal conductivity of EPDM/TiC and EPDM/TiC/POE composites were tested by thermal constants analyzing TSP 2500, supplied by Hot Disk.

\section{Results and discussion}

\subsection{FT-IR analysis}

Scheme 1 illustrates the surface modification process. NDZ105 firstly hydrolyzed to produce Ti-OH groups. Then, Ti-OH groups reacted with hydroxyl groups on surface of TiC particles via condensation reaction. ${ }^{[25]}$ The intention of this step is to introduce functional $\mathrm{C}=\mathrm{C}$ groups onto the surface of $\mathrm{TiC}$ particles, which is useful for the next cure process. ${ }^{[6]}$

In Figure 1, the absorption peak at around $3218 \mathrm{~cm}^{-1}$ confirms the existence of hydroxyl groups on surface of TiC particles. It is also observed that NDZ105 absorbs at $2917 \mathrm{~cm}^{-1}$ and $2850 \mathrm{~cm}^{-1}$, assigned to asymmetric stretching vibration of methylene and symmetric stretching vibration of methylene, respectively. ${ }^{[24,26]}$ The absorption 
peaks around $2917 \mathrm{~cm}^{-1}$ and $2850 \mathrm{~cm}^{-1}$ in the spectrum of modified TiC, suggest the adherence of NDZ105 to the surface of TiC particles. ${ }^{[20,27]}$

(Scheme 1)

(Fig. 1)

\subsection{DSC characteristic of EPDM/TiC gums}

Table 3 lists DSC characteristics of the EPDM/TiC and EPDM/TiC/POE gums. It is shown that only EPDM/TiC/POE (10/2/1) and EPDM/TiC/POE (10/2/2) has the onset melting temperature $\left(\mathrm{T}_{\mathrm{m}}^{\text {onset }}\right)$, peak melting temperature $\left(\mathrm{T}_{\mathrm{m}}^{\text {peak }}\right)$, final melting temperature $\left(\mathrm{T}_{\mathrm{m}}^{\text {final }}\right)$, melting enthalpy $(\Delta \mathrm{H})$ and crystallization degree $\left(\mathrm{X}_{\mathrm{c}}\right)$. EPDM is the random copolymer synthesized by ethylene, propylene and 5-ethylidene-2-norbornene, so there are no crystal lattices in EPDM control and EPDM/TiC gums. ${ }^{[8]}$

(Table 3)

\subsection{Bound rubber content of EPDM/TiC gums}

The bound rubber content of EPDM/TiC gums is listed in Table 4. The free rubber and ingredients from EPDM fraction can be extracted during bound rubber test. ${ }^{[11]}$ The bound rubber content of EPDM/TiC gums obeys the sequence: 


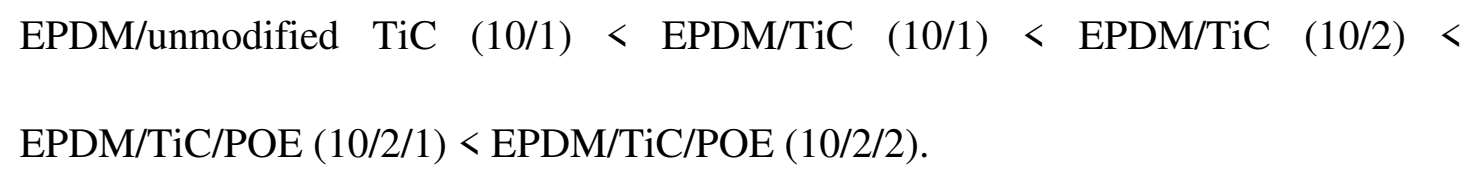

This is because that the molecular chains of NDZ105 on the surface of TiC can physically entangle with EPDM chains and improve the interfacial adhesion between TiC particles and EPDM matrix. ${ }^{[22]}$ Thus, the surface treatment of TiC particles can increase the bound rubber content of EPDM/unmodified TiC (10/1). With the increase of $\mathrm{TiC}$ content, bound rubber content of EPDM/TiC gums boost. The addition of POE into EPDM/TiC can further increase the bound rubber content. The reason is that the crystal lattices in POE cannot be extracted during the bound rubber test. ${ }^{[27-28]}$

(Table 4)

\subsection{Rheological properties of EPDM/TiC gums}

Figure 2 illustrates the relation of frequency versus complex viscosity and storage modulus $\left(G^{\prime}\right)$. It is shown that with the increased frequency, the complex viscosity of EPDM/TiC gums decrease. In contrast, the G' boosts with the increased frequency. The dependence of complex viscosity and $G^{\prime}$ at $1.7 \mathrm{~Hz}$ follow the sequence: EPDM control < EPDM/unmodified TiC $(10 / 1)<$ EPDM/TiC $(10 / 1)<$ EPDM/TiC/POE (10/2/2) < EPDM/TiC/POE (10/2/1) < EPDM/TiC (10/2).

The molecular chains of NDZ105 on surface of TiC can physically entangle with EPDM chains. Thus, $10 \%$ modified TiC can endow EPDM with higher complex viscosity and G' value than $10 \%$ unmodified TiC. The $20 \%$ modified TiC particles 
can increase the complex viscosity of EPDM control from $16000 \mathrm{~Pa} \cdot \mathrm{S}$ to $119000 \mathrm{~Pa} \cdot \mathrm{S}$ (6.4 times increase) at $1.7 \mathrm{~Hz} .^{[6,15]}$

By comparison, the crystal lattices in POE can melt under the testing temperature of rheological properties $\left(100^{\circ} \mathrm{C}\right)$. The melted crystal lattices can act as internal lubricants in EPDM/TiC/POE gums, which decreases the complex viscosity of EPDM/TiC (10/2). It is shown that $10 \%$ POE and 20\% POE can decrease the complex viscosity of EPDM/TiC (10/2) from $119000 \mathrm{~Pa} \cdot \mathrm{S}$ to $94200 \mathrm{~Pa} \cdot \mathrm{S}$ (20\% decrease) and $57800 \mathrm{~Pa} \cdot \mathrm{S}(51 \%$ decrease) at $1.7 \mathrm{~Hz}$, respectively. In this way, the processing fluidity of EPDM/TiC (10/2) gum can be improved by the addition of POE. ${ }^{[1,23]}$

(Fig. 2)

\subsection{Cure properties of EPDM/TiC composites}

The cure curves and data of EPDM with TiC and POE are shown in Figure 3 and Table 5, respectively. It is illustrated that the cure curves of EPDM gums firstly decrease and then increase due to the formation of chemical crosslink points. ${ }^{[24]}$ It is listed in Table 5 that the maximum toque $\left(\mathrm{M}_{\mathrm{H}}\right)$ and cure rate of EPDM/TiC follow the order: EPDM control < EPDM/unmodified TiC (10/1) < EPDM/TiC $(10 / 1)<$ EPDM/TiC/POE (10/2/2) < EPDM/TiC/POE (10/2/1) < EPDM/TiC (10/2).

It is illustrated that the surface modification of $\mathrm{TiC}$ can enhance the $\mathrm{M}_{\mathrm{H}}$ and cure rate of EPDM/unmodified $\mathrm{TiC}(10 / 1)$. There are $\mathrm{C}=\mathrm{C}$ groups in NDZ105 on the surface of modified TiC particles which can participate into the vulcanization process 
of EPDM and form extra crosslinks, leading to the increase of $\mathrm{M}_{\mathrm{H}}$ and cure rate. ${ }^{[18,28]}$ Moreover, with the increased amount of modified $\mathrm{TiC}$, the $\mathrm{M}_{\mathrm{H}}$ and cure rate further increase.

Although EPDM/TiC (10/2), EPDM/TiC/POE (10/2/1) and EPDM/TiC/POE (10/2/2) have the same amount of modified TiC particles, the $\mathrm{M}_{\mathrm{H}}$ of them are different. The reason is that the $\mathrm{M}_{\mathrm{H}}$ is correlated with both complex viscosity and chemical crosslinks of EPDM composites. ${ }^{[29-30]}$ It has been shown that the addition of $10 \%$ and $20 \%$ POE can decrease the complex viscosity of EPDM/TiC (10/2) by $20 \%$ and $51 \%$ at the testing frequency of cure curves $(1.7 \mathrm{~Hz})$, respectively. Thereby, the $\mathrm{M}_{\mathrm{H}}$ of EPDM/TiC/POE (10/2/1) and EPDM/TiC/POE (10/2/2) are lower than that of $\operatorname{EPDM} / \mathrm{TiC}(10 / 2)$.

(Fig. 3)

(Table 5)

\subsection{Crosslink density of EPDM/TiC composites}

The crosslink density of EPDM/TiC composites with different amount of modified TiC is listed in Table 6 and follows the sequence: EPDM control < EPDM/unmodified TiC (10/1) < EPDM/TiC (10/1) < EPDM/TiC (10/2) < EPDM/TiC/POE (10/2/1) < EPDM/TiC/POE (10/2/2).

The trend of crosslink density of EPDM/TiC composites is partially consistent with the trend of $\mathrm{M}_{\mathrm{H}}$ of EPDM/TiC composites. There are extra chemical crosslink points formed by functional $\mathrm{C}=\mathrm{C}$ groups in NDZ105 on the surface of modified TiC 
particles. ${ }^{[31]}$ Thus, the surface modification of TiC and increased amount of modified TiC can increase the crosslink density of EPDM/TiC composites.

Although the $\mathrm{M}_{\mathrm{H}}$ of EPDM/TiC/POE (10/2/2) is lower than that of EPDM/TiC (10/2), the crosslink density of EPDM/TiC/POE (10/2/2) is higher than that of EPDM/TiC (10/2). The crosslink density is consisted of both physical and chemical crosslink points. ${ }^{[7,28]}$ The crystal lattices cannot melt at the temperature of solvent swell test $\left(23^{\circ} \mathrm{C}\right)$, and can act as physical crosslink points for EPDM/TiC/POE composites. ${ }^{[32]}$ In this way, EPDM/TiC/POE (10/2/2) has the highest physical and chemical crosslink density among all samples.

(Table 6)

\subsection{Dispersion of TiC particles in EPDM/TiC composites}

Scanning electron micrographs of TiC dispersed in EPDM matrix are illustrated in Figure 4. The surface treatment of TiC can reduce the aggregation to some extent. What's more, the POE has a good compatibility with EPDM matrix, because the they have the similar molecular structure. ${ }^{[24,28]}$

(Fig. 4)

\subsection{Mechanical properties of EPDM/TiC composites}

Data of mechanical properties of EPDM with modified TiC are listed in Table 7. 
It is apparent that the addition of $\mathrm{TiC}$ particles can improve the hardness, tensile and tear strength of EPDM/TiC composites. It is shown that the hardness, tensile and tear strength of EPDM/TiC composites follow the order: EPDM control < EPDM/unmodified TiC $(10 / 1)<\operatorname{EPDM} / \mathrm{TiC}(10 / 1)<\operatorname{EPDM} / \mathrm{TiC}(10 / 2)<$ EPDM/TiC/POE (10/2/1) < EPDM/TiC/POE (10/2/2).

The 10\% unmodified TiC cannot reinforce the EPDM control. By comparison, only 1\% NDZ105 can increase the tensile and tear strength of EPDM/unmodified TiC (10/1) from 1.43 MPa and $8.86 \mathrm{kN} / \mathrm{m}$ to $3.51 \mathrm{MPa}(145 \%$ increase) and $12.61 \mathrm{kN} / \mathrm{m}$ ( $42 \%$ increase), respectively. This is ascribed to the fact that the $\mathrm{C}=\mathrm{C}$ groups in NDZ105 can participate into the cure process and then increase the crosslink density of EPDM/TiC (10/1) composite. ${ }^{[33]}$ When the amount of modified TiC increase to $20 \%$, the tensile and tear strength of EPDM/TiC (10/2) further increase to $4.63 \mathrm{MPa}$ and $13.57 \mathrm{kN} / \mathrm{m}$.

Due to the presence of crystal lattices in POE, EPDM/TiC/POE (10/2/1) and EPDM/TiC/POE (10/2/2) composites have extra physical crosslink points than EPDM/TiC (10/2) composite. The crystal lattices in EPDM/TiC/POE (10/2/2) can provide extra strength to resist outside forces like chemical crosslink points. ${ }^{[9,28]}$ The 20\% POE can increase the tensile and tear strength of EPDM/TiC (10/2) composite from 4.63 MPa and $13.57 \mathrm{kN} / \mathrm{m}$ to $8.33 \mathrm{MPa}(92 \%$ increase) and $18.80 \mathrm{kN} / \mathrm{m}(38 \%$ increase), respectively.

(Table 7)

\subsection{Dielectric properties of EPDM/TiC composites}


Figure 5 presents dielectric constant and dielectric loss factor curves of EPDM/TiC composites. The dielectric constant and dielectric loss factor of EPDM/TiC composites at the same frequency obey the sequence: EPDM control < EPDM/unmodified TiC (10/1) < EPDM/TiC (10/1) < EPDM/TiC (10/2) < EPDM/TiC/POE (10/2/1) < EPDM/TiC/POE (10/2/2).

A model is proposed in Figure 6 to explain the trend. The dielectric constant of unmodified $\mathrm{TiC}$ is higher than that of EPDM control. ${ }^{[7,}{ }^{18]}$ Thus, the EPDM/unmodified TiC (10/1) has higher dielectric constant than EPDM control. The polar oleic groups in NDZ105 can increase the polarity of modified TiC particles. Thereby, the 20\% modified TiC particles can increase the dielectric constant of EPDM control from 2.4 to 8.7 (360\% increase) at $10^{5} \mathrm{~Hz}$.

The addition of 20\% POE can increase the dielectric constant of EPDM/TiC (10/2) from 8.7 to 13.5 (55\% increase), at $10^{5} \mathrm{~Hz}$. The reason is that the presence of crystal lattices in POE can provide extra interfacial polarity between amorphous phase and crystal lattices at the testing temperature of dielectric constant $\left(23{ }^{\circ} \mathrm{C}\right)$. So the overall polarity in EPDM/TiC/POE (10/2/2) is enhanced, leading to the increase of dielectric constant of EPDM/TiC/POE (10/2/2) composite..$^{[28,34]}$

The dielectric loss factors of composites are all below 0.1, indicating that the dielectric loss is 10 times or 100 times lower than dielectric constant of EPDM composites. This phenomenon demonstrates that the energy lost in the excited electric field is very low. ${ }^{[35-36]}$ 
(Fig. 5)

(Fig. 6)

\subsection{Volume and surface resistivity of EPDM/TiC composites}

Due to the non-polar structure of EPDM, the motion of current carriers in EPDM matrix is very difficult. It is shown in Table 8 that the addition of unmodified and modified TiC can decrease the surface and volume resistivity of EPDM composites to some extent. The reason is that the electric conductivity of $\mathrm{TiC}$ particles is higher than that of EPDM. ${ }^{[37]}$ The addition of $20 \%$ modified TiC can decrease the surface and volume resistivity of EPDM control from $5.0 \times 10^{12} \Omega$ and $1.5 \times 10^{15} \Omega \cdot \mathrm{m}$ to $3.7 \times 10^{11} \Omega$ ( 1 order of magnitude decrease) and $4.7 \times 10^{12} \Omega \cdot \mathrm{m}$ ( 3 order of magnitude decrease), respectively.

With the addition of POE, the crystal lattices in POE will connect the surrounding TiC particles, providing more inter-connective pathways or conductive channels in the matrix, which is shown in Figure 6 D. The $20 \%$ POE can facilitate the motion of current carriers in the composites. The surface and volume resistivity of EPDM/TiC (10/2) slightly decrease from $3.7 \times 10^{11} \Omega$ and $4.7 \times 10^{12} \Omega \cdot \mathrm{m}$ to $1.3 \times 10^{11} \Omega$ and $1.7 \times 10^{12} \Omega \cdot \mathrm{m}$, respectively. Compared with TiC particles, POE can increase the dielectric constant of EPDM without greatly decreasing the volume resistivity of EPDM composites.

In addition, the volume resistivity of EPDM/TiC/POE(10/2/2) is still higher than $10^{9} \Omega \cdot \mathrm{m}$, indicating that it can be regarded as non-conductive material. ${ }^{[38]}$ 
(Table 8)

\subsection{Thermal conductivity of EPDM/TiC composites}

Table 9 shows the thermal conductivity of EPDM/TiC and EPDM/TiC/POE composites. It is observed that the addition of $20 \%$ NDZ105 modified TiC can raise the thermal conductivity of EPDM control from $0.239 \mathrm{~W} /(\mathrm{m} \cdot \mathrm{K})$ to $0.281 \mathrm{~W} /(\mathrm{m} \cdot \mathrm{K})$ (almost 17\% increase). This is because that TiC particles have higher thermal conductivity than EPDM.

The addition of $20 \%$ POE can further boost the thermal conductivity of EPDM/TiC (10/2) from $0.281 \mathrm{~W} /(\mathrm{m} \cdot \mathrm{K})$ to $0.416 \mathrm{~W} /(\mathrm{m} \cdot \mathrm{K})(48 \%$ increase $)$. The reason is that the crystal lattices in POE can partially connect surrounding TiC particles, as shown in Figure 6 D. Such connection can provide extra passage among surrounding TiC particles to facilitate the conduction of heat in EPDM. ${ }^{[16]}$

(Table 9)

\section{Conclusions}

In this work, EPDM/TiC/POE (10/2/2) composite with excellent processing fluidity, improved dielectric, thermal, electrical and mechanical properties is prepared. The $20 \%$ modified TiC particles can increase the complex viscosity of EPDM control from $16000 \mathrm{~Pa} \cdot \mathrm{S}$ to $119000 \mathrm{~Pa} \cdot \mathrm{S}(6.4$ times increase) at $1.7 \mathrm{~Hz}$. In contrast, the $20 \%$

POE can decrease the complex viscosity of EPDM/TiC (10/2) from $119000 \mathrm{~Pa} \cdot \mathrm{S}$ to 
$57800 \mathrm{~Pa} \cdot \mathrm{S}(51 \%$ decrease) at $1.7 \mathrm{~Hz}$.

The 20\% modified TiC particles can increase the dielectric constant of EPDM control from 2.4 to 8.7 (360\% increase) at $10^{5} \mathrm{~Hz}$, with the decrease of volume resistivity by 3 order of magnitude. By comparison, the addition of $20 \%$ POE can further increase the dielectric constant of EPDM/TiC (10/2) from 8.7 to 13.5 (55\% increase) at $10^{5} \mathrm{~Hz}$, with slight decrease of volume resistivity.

In terms of thermal conductivity, the addition of $20 \%$ NDZ105 modified TiC can raise the thermal conductivity of EPDM control from $0.239 \mathrm{~W} /(\mathrm{m} \cdot \mathrm{K})$ to 0.281 $\mathrm{W} /(\mathrm{m} \cdot \mathrm{K})$ (only $17 \%$ increase), while the addition of $20 \%$ POE can further boost the thermal conductivity of EPDM/TiC $(10 / 2)$ from $0.281 \mathrm{~W} /(\mathrm{m} \cdot \mathrm{K})$ to $0.416 \mathrm{~W} /(\mathrm{m} \cdot \mathrm{K})$ (48\% increase).

The addition of $20 \%$ modified TiC particles and $20 \%$ POE can boost the tensile and tear strength of EPDM control from 1.38 MPa and 8.01 kN/m to $8.33 \mathrm{MPa}(600 \%$ increase) and $18.80 \mathrm{kN} / \mathrm{m}$ (234\% increase), respectively.

\section{Acknowledgment}

The work is supported by Jiangsu Overseas Visiting Scholar Program for University Prominent Young \& Middle-aged Teachers and Presidents; The Jiangsu precision manufacturing engineering technology research and Development Center, Nanjing Institution of Industry Technology (ZK15-01-06); Top-notch Academic Programs Project of Jiangsu Higher Education Institutions(TAPP), PPZY2015A087. 


\section{References}

1. J. Su; J. Zhang, J. Polym. Sci., Part B: Polym. Phys. 15, 1101 (2018).

2. V. Kolbunov, R.; A. Tonkoshkur, S.; I. Gomilko, V., J. Mater. Sci. - Mater. Electron. 11, 8322 (2017).

3. M. Molberg; D. Crespy; P. Rupper; F. Nüesch; J.-A. E. Månson; C. Löwe; D. M. Opris, Adv. Funct. Mater. 19, 3280 (2010).

4. Z. Wang; W. Zhou; X. Sui; L. Dong, J. Reinf. Plast. Compos. 14, 1126 (2015).

5. J. Huang; S. Shian; Z. Suo; D. R. Clarke, Adv. Funct. Mater. 40, 5056 (2013).

6. J. Su; J. Zhang, Compos. Part B 7, 148 (2017).

7. F. B. Madsen; S. B. Zakaria; L. Yu; A. L. Skov, Adv. Eng. Mater. 7, 1154 (2016).

8. J. Su; J. Zhang, Plast., Rubb. Compos. 3, 127 (2016).

9. T. Lin; S. Li; J. Ke; Y. Zheng; Y. Yu, Adv. Eng. Mater. 7, 1800051 (2018).

10. J. Su; J. Zhang, J. Mater. Sci. - Mater. Electron. 5, 4344 (2016).

11. J. Su; J. Zhang, J. Mater. Sci. - Mater. Electron. 7, 5250 (2017).

12. J. Kruželák; R. Sýkora; R. Dosoudil; I. Hudec, Adv. Mater. Sci. Eng. 3, 1 (2016).

13. Y. Wang; S. Zhou; H. Du, J. Mater. Sci. - Mater. Electron. 14, 12360 (2018).

14. M. Khan, Saleem; Khattak, Noor, Saeed; Sohail, Muhammad, J. Mater. Sci. - Mater. Electron. 2, 1997 (2017).

15. A. L. Skov; L. Yu, Adv. Eng. Mater. 5, 1700762 (2018).

16. M. Li; C. Tang; L. Zhang, J. Mater. Sci. - Mater. Electron. 6, 4948 (2018).

17. J. Su; J. Zhang, Appl. Surf. Sci. 2, 531 (2016).

18. O. O. Okudur; K. Vanstreels; I. de Wolf, Adv. Eng. Mater. 8, 1600653 (2017).

19. K. H. Rahiman; G. Unnikrishnan; A. Sujith; C. K. Radhakrishnan, Mater. Lett. 6, 633 (2005).

20. S. Pongdhorn; S. B. Chakrit; K. Hatthapanit; U. Thepsuwan, Polym. Test. 4, 439 (2005).

21. P. Sae-oui; C. Sirisinha; U. Thepsuwan; K. Hatthapanit, Polym. Test. 8, 871 (2004).

22. J. Su; J. Zhang, J. Appl. Polym. Sci. 19, 44831 (2017).

23. H. Silau; N. B. Stabell; F. R. Petersen; M. Pham; L. Yu; A. L. Skov, Adv. Eng. Mater. 9, 1800241 (2018).

24. J. Su; J. Zhang, RSC Adv. 96, 78448 (2015).

25. B. Kussmaul; S. Risse; G. Kofod; R. Waché; M. Wegener; D. N. McCarthy; H. Krüger; R. Gerhard, Adv. Funct. Mater. 23, 4589 (2011).

26. S. Yu; G. Wang, J. Polym. Sci., Part B: Polym. Phys. 12, 948 (2017).

27. C. Nakason; P. Wannavilai; A. Kaesaman, Polym. Test. 1, 34 (2006).

28. J. Su; S. Chen; J. Zhang, Polym. Test. 2, 195 (2010).

29. J. Su; S. Chen; J. Zhang; Z. Xu, Polym. Test. 3, 235 (2009).

30. A. Rathi; M. Hernández; S. J. Garcia; W. K. Dierkes; J. W. M. Noordermeer; C. Bergmann; J. Trimbach; A. Blume, J. Polym. Sci., Part B: Polym. Phys. 11, 842 (2018).

31. P. H. Vargantwar; A. E. Özçam; T. K. Ghosh; R. J. Spontak, Adv. Funct. Mater. 10, 2100 (2012).

32. D. M. Opris; M. Molberg; C. Walder; Y. S. Ko; B. Fischer; F. A. Nüesch, Adv. Funct. Mater. 18, 3531 (2011).

33. M.-F. Lin; V. K. Thakur; E. J. Tanb; P. S. Lee, RSC Adv. 3, 576 (2011).

34. J. Chen; X. Yu; F. Yang, J. Mater. Sci. - Mater. Electron. 11, 8043 (2017).

35. X.-L. Hu; W.-B. Luo; X. Liu; M. Li; Y.-J. Huang; J.-L. Bu, Plast., Rubb. Compos. 10, 416 (2013).

36. I. Kang; M. A. Khaleque; Y. Yoo; P. J. Yoon; S.-Y. Kim; K. T. Lim, Compos. Part A 6, 623 (2011).

37. O. Abdullah, Gh.; R. Hanna, R.; Y. Salman, A., K., J. Mater. Sci. - Mater. Electron. 14, 10283 
(2017).

38. S. V. Ganesan; K. K. Mothilal; S. Selvasekarapandian, J. Mater. Sci. - Mater. Electron. 10, 8089 (2018). 
Figure captions

Scheme 1 Schematic diagram for surface modification of TiC

Figure 1 FT-IR spectrum of TiC particles before and after surface modification

Figure 2 The rheological properties of EPDM/TiC composites: A. complex viscosity; B. storage modulus (G');

Figure 3 Cure curves of EPDM/TiC composites

Figure 4 SEM micrographs of EPDM composites: A. EPDM/unmodified TiC (10/1); B. EPDM/TiC (10/1); C. EPDM/TiC (10/2); D. EPDM/TiC/POE (10/2/2);

Figure 5 Dielectric properties of EPDM/TiC composites: A. Dielectric constant; B. Dielectric loss factor

Figure 6 Model of dispersion of TiC and POE in EPDM composites: A. EPDM/unmodified TiC (10/1); B. EPDM/TiC (10/1); C. EPDM/TiC (10/2); D. EPDM/TiC/POE (10/2/2) 


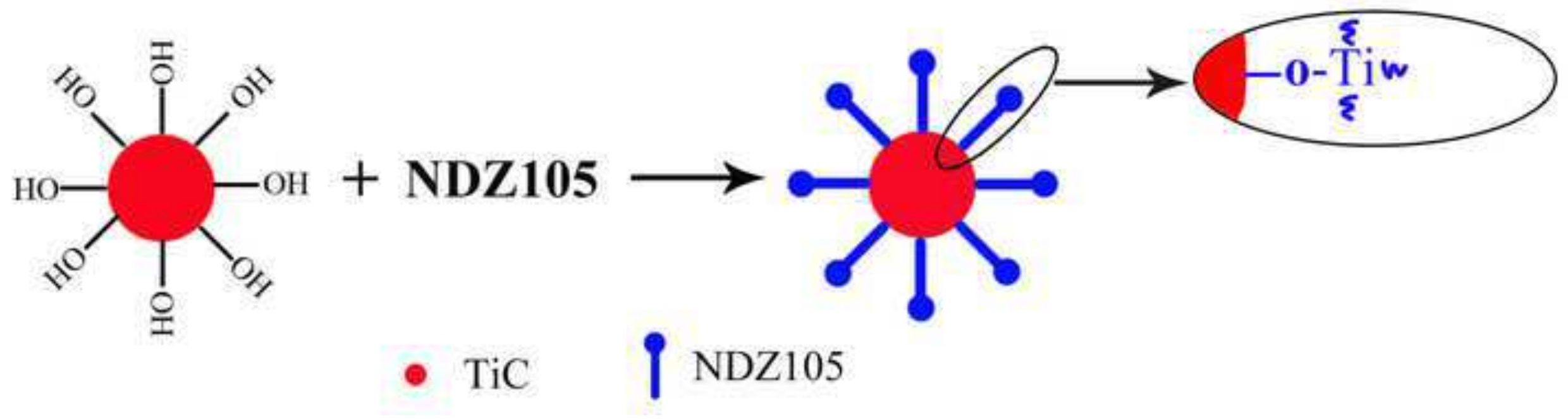




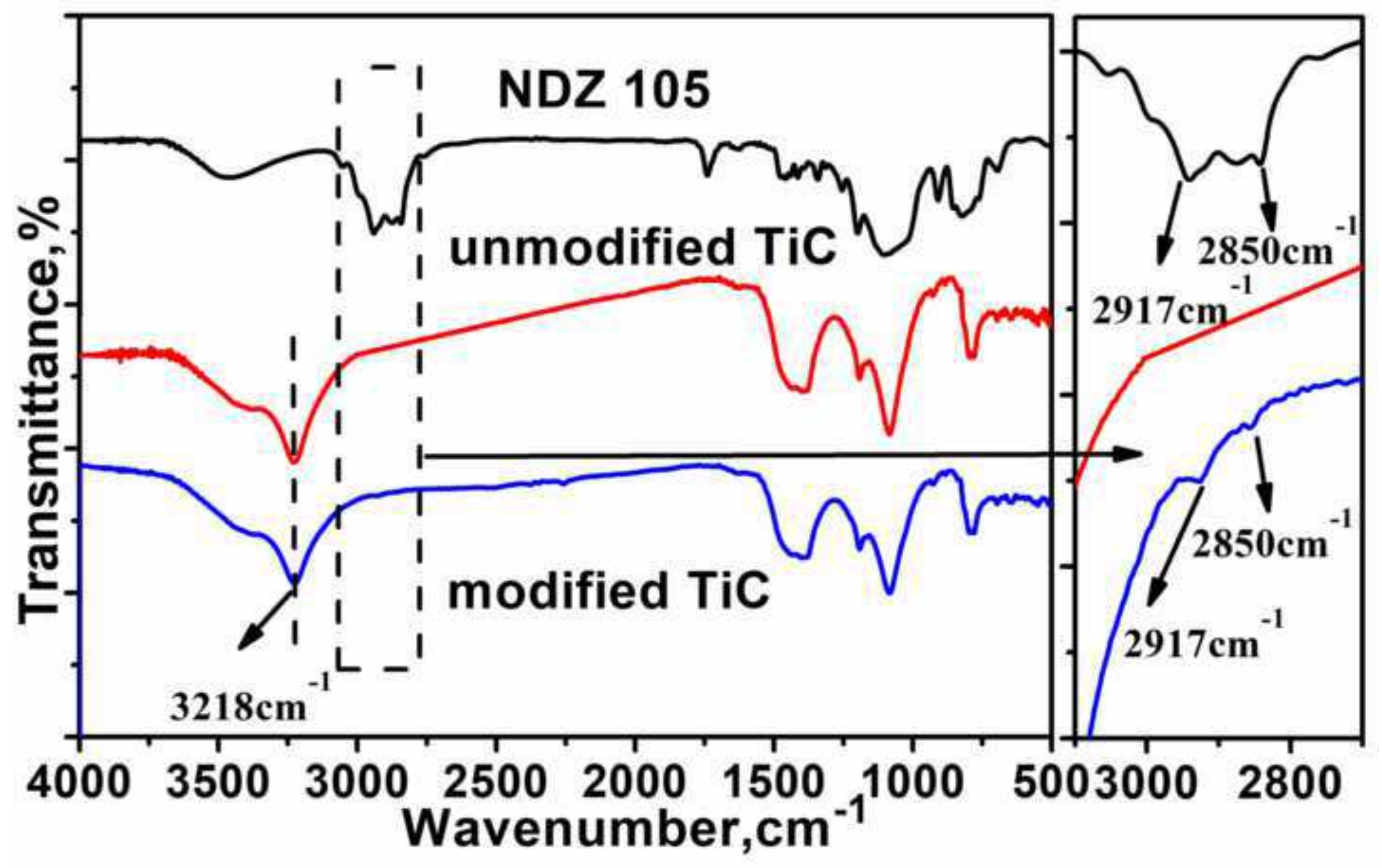



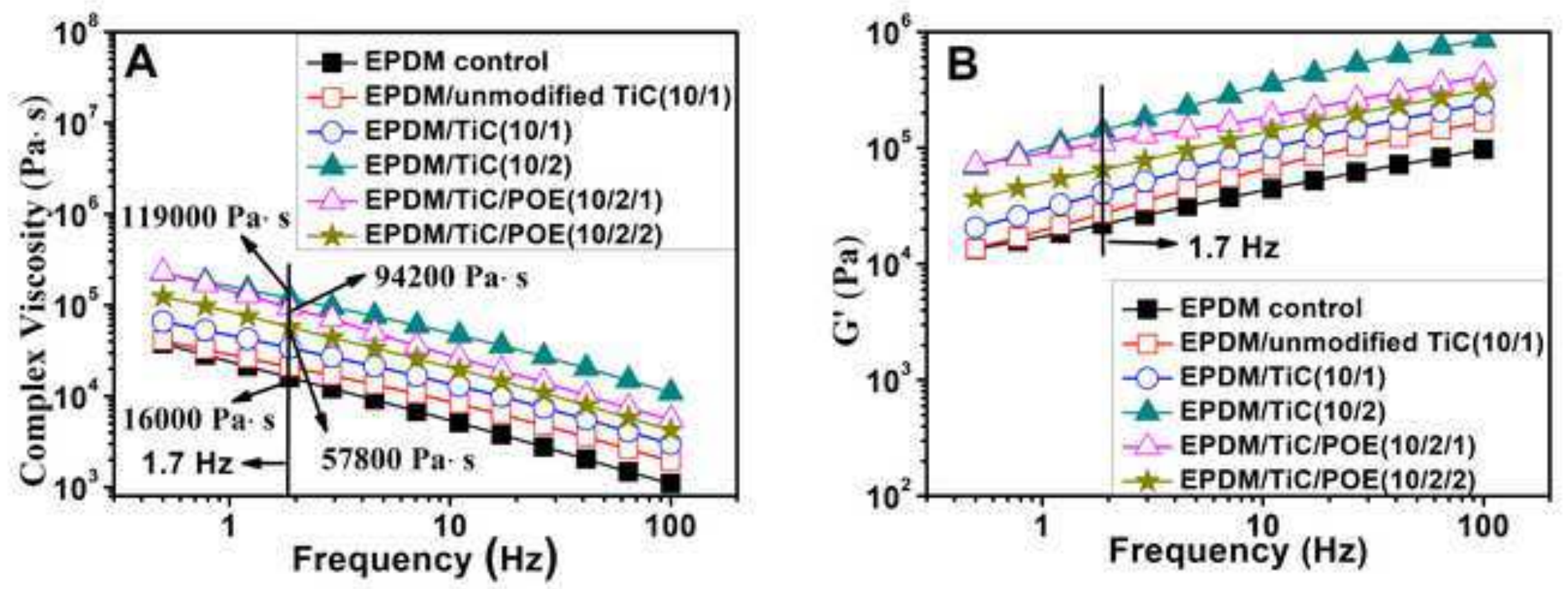


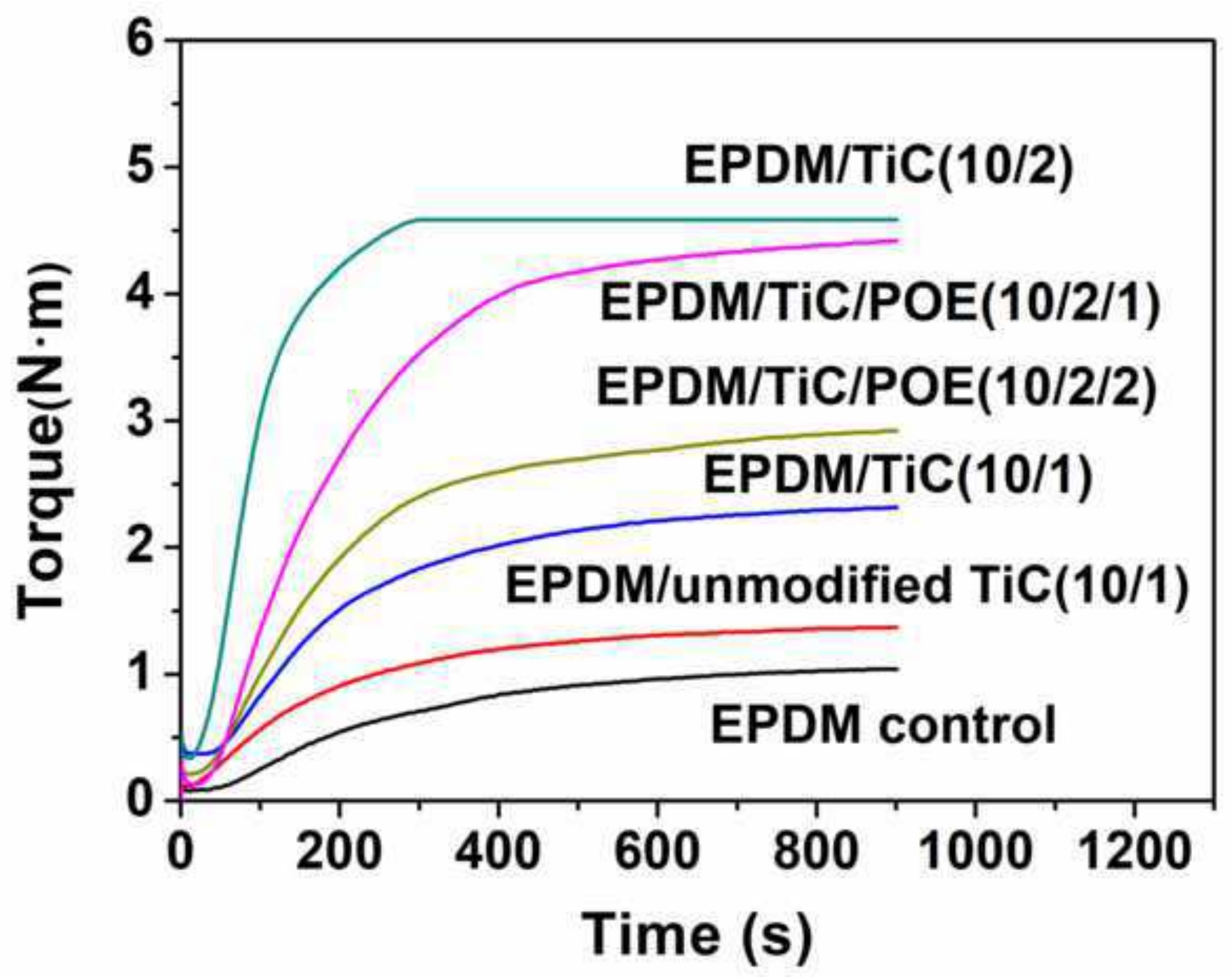




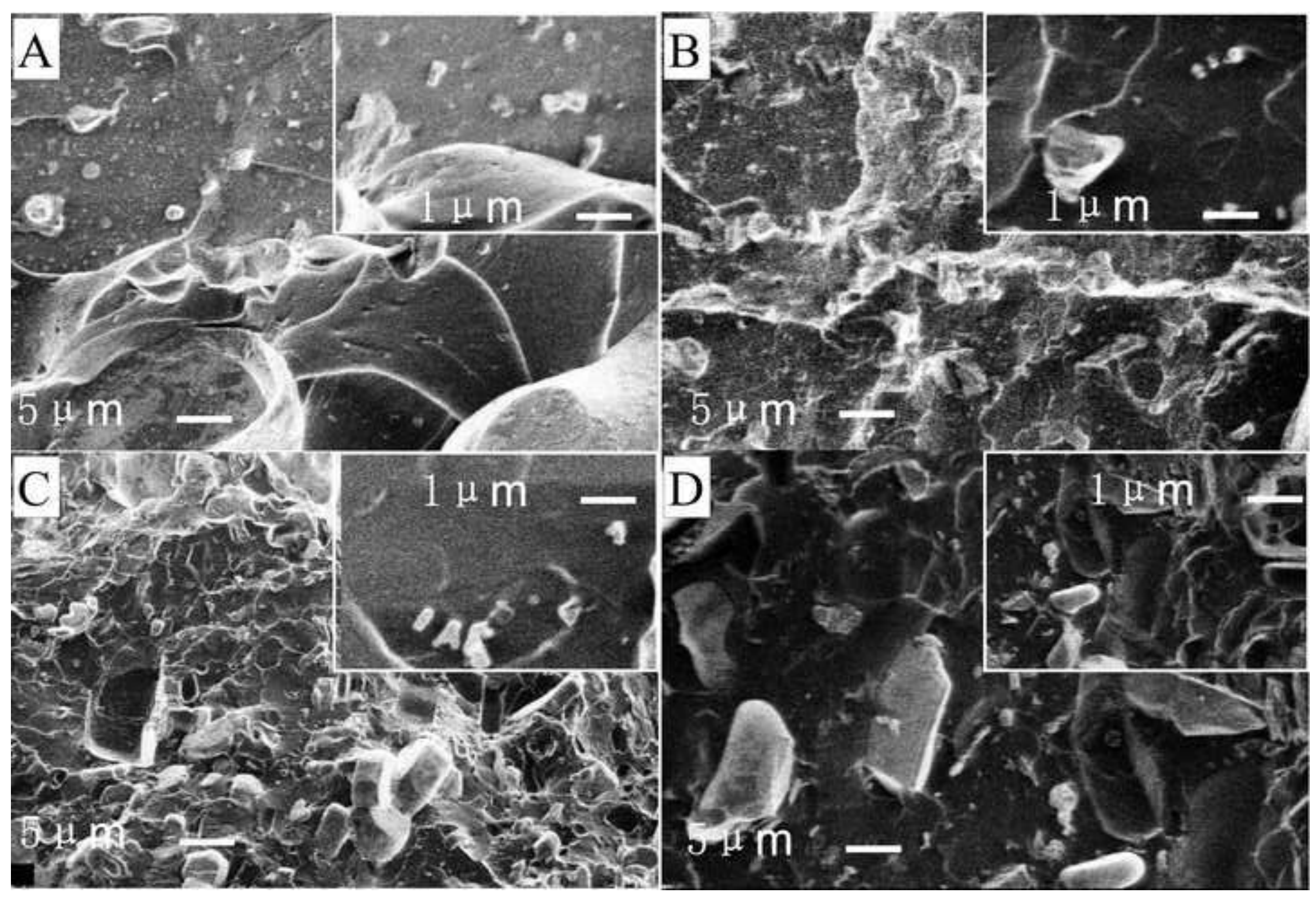



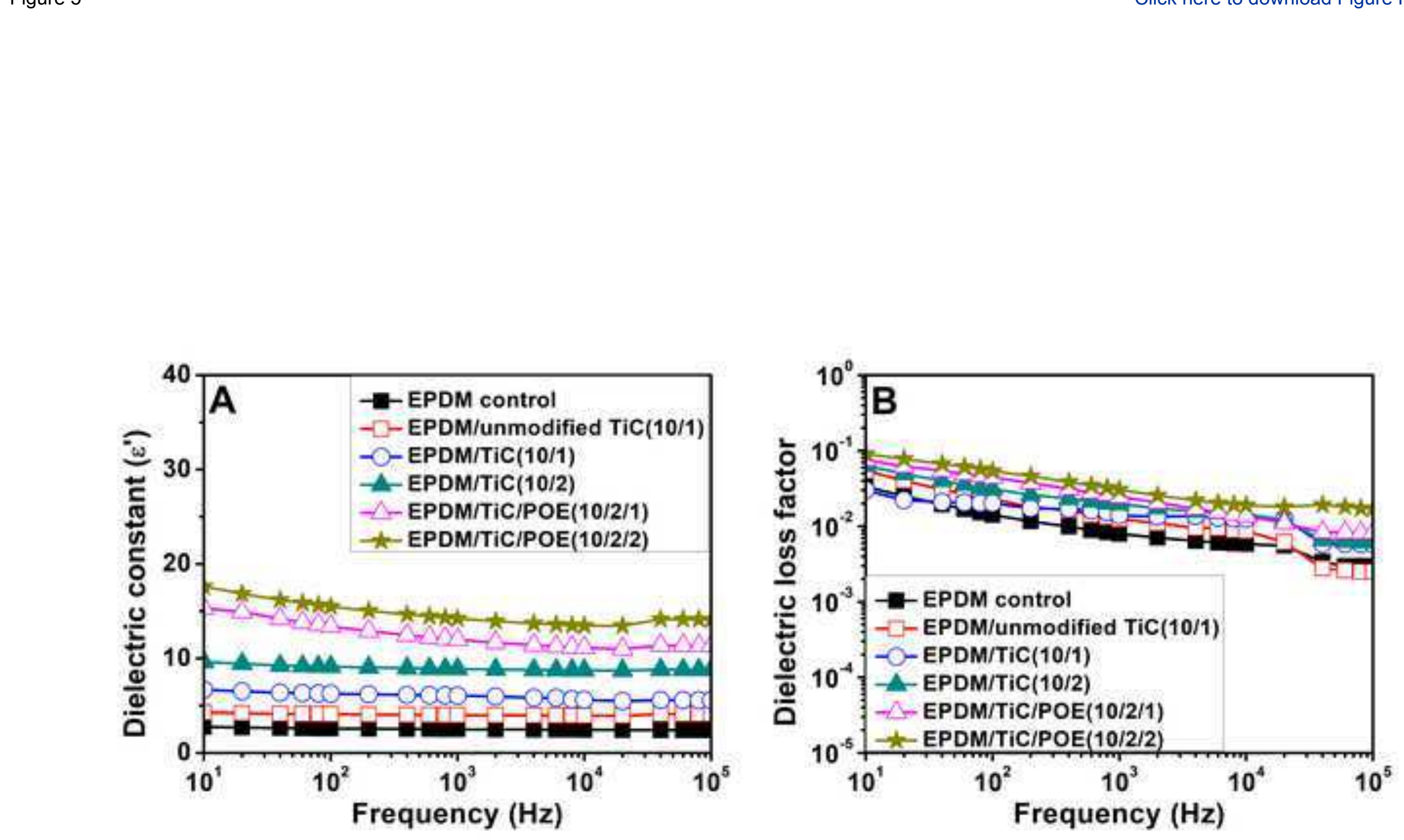

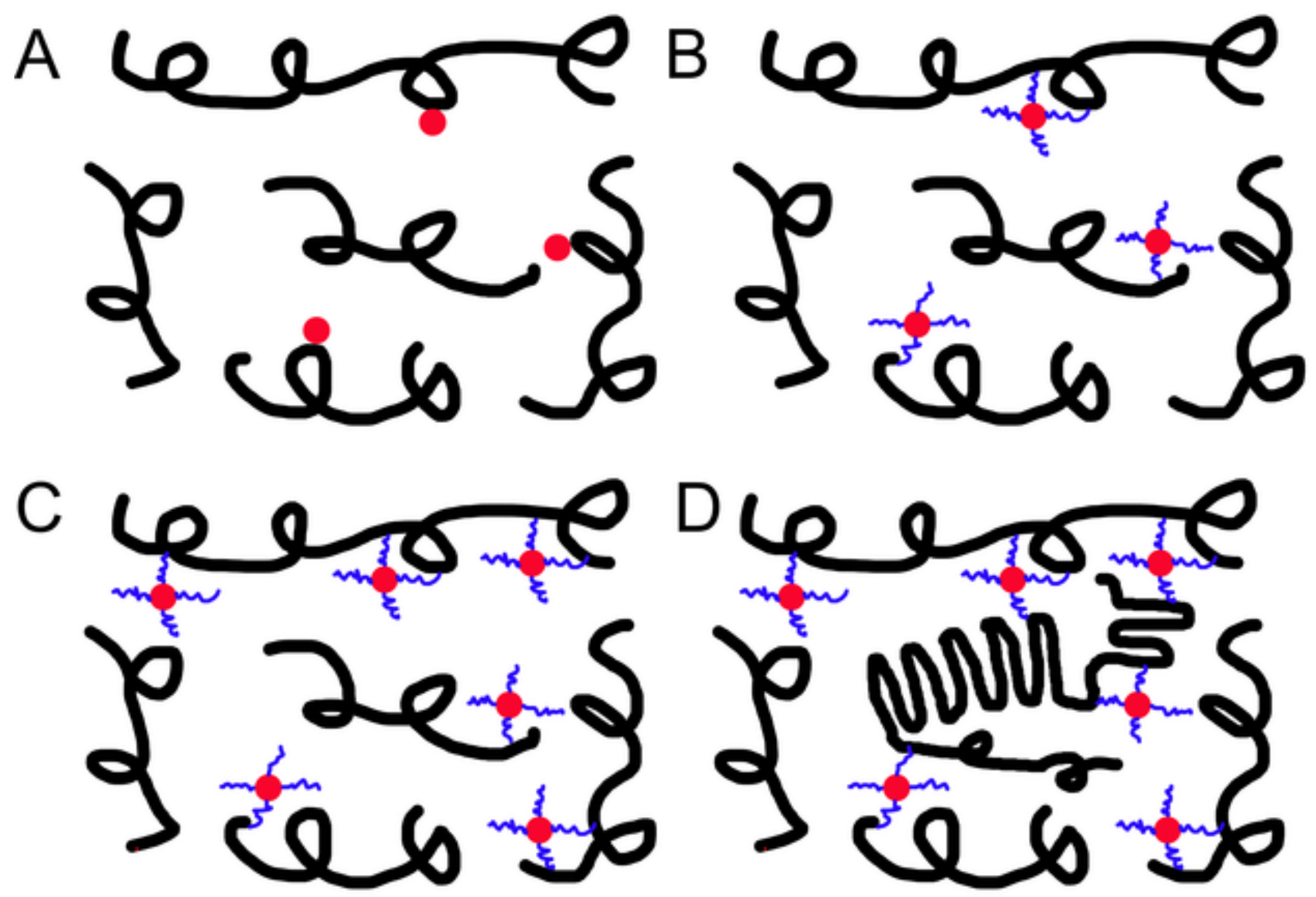

Random coil U

Crystal lattices in POE 
Table 1 Chemical/commercial name and structure of coupling agents

Chemical/commercial name Molecular structure


Table 2 Formulation of EPDM/TiC composites (phr)

\begin{tabular}{cccccccccc}
\hline No. & EPDM & Control & $\begin{array}{c}\text { unmodified } \\
\text { TiC }\end{array}$ & $\begin{array}{c}\text { NDZ105 modified } \\
\text { TiC }\end{array}$ & POE & ZnO & SA & DCP & MB \\
\hline A & 100 & - & - & - & - & 5 & 1 & 4 & 1 \\
B & 100 & - & 10 & - & - & 5 & 1 & 4 & 1 \\
C & 100 & - & - & 10 & - & 5 & 1 & 4 & 1 \\
D & 100 & - & - & 20 & - & 5 & 1 & 4 & 1 \\
E & 100 & - & - & 20 & 10 & 5 & 1 & 4 & 1 \\
F & 100 & - & - & 20 & 20 & 5 & 1 & 4 & 1 \\
\hline
\end{tabular}


Table 3 DSC characteristics of EPDM/TiC gums

\begin{tabular}{|c|c|c|c|c|c|}
\hline \multirow{2}{*}{ Sample } & $\mathrm{T}_{\mathrm{m}}^{\text {onset }}$ & $\mathrm{T}_{\mathrm{m}}^{\text {peak }}$ & $\mathrm{T}_{\mathrm{m}}^{\text {final }}$ & $\Delta \mathrm{H}$ & $\mathrm{Xc}$ \\
\hline & $\left({ }^{\circ} \mathrm{C}\right)$ & $\left({ }^{\circ} \mathrm{C}\right)$ & $\left({ }^{\circ} \mathrm{C}\right)$ & $(\mathrm{J} / \mathrm{g})$ & $(\%)$ \\
\hline EPDM control & - & - & - & - & - \\
\hline $\begin{array}{c}\text { EPDM/unmodified TiC } \\
(10 / 1)\end{array}$ & - & - & - & - & - \\
\hline EPDM/TiC (10/1) & - & - & - & - & - \\
\hline EPDM/TiC (10/2) & - & - & - & - & - \\
\hline $\begin{array}{c}\text { EPDM/TiC/POE } \\
(10 / 2 / 1)\end{array}$ & 46.5 & 78.4 & 93.1 & 2.1 & 9.8 \\
\hline $\begin{array}{c}\text { EPDM/TiC/POE } \\
(10 / 2 / 2)\end{array}$ & 47.1 & 80.9 & 94.2 & 8.0 & 20 \\
\hline
\end{tabular}

$\mathrm{T}_{\mathrm{m}}^{\text {onset }}$ : onset melting temperature; $T_{\mathrm{m}}^{\text {peak }}:$ peak position in melting temperature range; $\mathrm{T}_{\mathrm{m}}^{\text {final }}:$ final melting temperature; $\Delta \mathrm{H}$ : enthalpy of fusion; Xc: relative crystallinity; 
Table 4 Bound rubber content of EPDM/TiC composites

\begin{tabular}{cc}
\hline Sample & Bound rubber content $(\%)$ \\
\hline EPDM/unmodified TiC (10/1) & 11 \\
EPDM/TiC (10/1) & 15 \\
EPDM/TiC (10/2) & 20 \\
EPDM/TiC/POE (10/2/1) & 23 \\
EPDM/TiC/POE (10/2/2) & 27 \\
\hline
\end{tabular}


Table 5 Cure characteristics of EPDM/TiC composites

\begin{tabular}{cccccc}
\hline Sample & $\mathrm{M}_{\mathrm{L}}$ & $\mathrm{t}_{\mathrm{ML}}$ & $\mathrm{M}_{\mathrm{H}}$ & $\mathrm{t}_{\mathrm{MH}}$ & $\begin{array}{c}\text { Cure rate } \\
\mathrm{N} \cdot \mathrm{m}\end{array}$ \\
$\mathrm{min}$ & $\mathrm{N} \cdot \mathrm{m}$ & $\mathrm{min}$ & $\mathrm{N} \cdot \mathrm{m} \cdot \mathrm{min}^{-1}$ \\
\hline EPDM control & 0.08 & 0.20 & 1.04 & 14.65 & 0.0664 \\
EPDM/unmodified TiC (10/1) & 0.12 & 0.37 & 1.37 & 14.86 & 0.0862 \\
EPDM/TiC (10/1) & 0.15 & 0.22 & 2.31 & 14.67 & 0.1494 \\
EPDM/TiC (10/2) & 0.37 & 0.12 & 4.58 & 13.91 & 0.3052 \\
EPDM/TiC/POE (10/2/1) & 0.26 & 0.28 & 4.42 & 14.72 & 0.2880 \\
EPDM/TiC/POE (10/2/2) & 0.21 & 0.33 & 2.92 & 14.83 & 0.1868 \\
\hline
\end{tabular}

$\mathrm{M}_{\mathrm{L}}$ : minimum torque; $\mathrm{t}_{\mathrm{ML}}$ : time to minimum torque; $\mathrm{M}_{\mathrm{H}}$ : maximum torque; $\mathrm{t}_{\mathrm{MH}}$ : time to maximum torque; Cure rate: $\left(\mathrm{M}_{\mathrm{H}^{-}} \mathrm{M}_{\mathrm{L}}\right) /\left(\mathrm{t}_{\mathrm{MH}} \mathrm{t}_{\mathrm{ML}}\right)$. 
Table 6 Crosslink density of EPDM/TiC composites

\begin{tabular}{cc}
\hline Sample & Crosslink density $\left(\mathrm{mol} \cdot \mathrm{cm}^{-3}\right)$ \\
\hline EPDM control & 0.000155 \\
EPDM/unmodified TiC (10/1) & 0.000185 \\
EPDM/TiC (10/1) & 0.000223 \\
EPDM/TiC (10/2) & 0.000271 \\
EPDM/TiC/POE (10/2/1) & 0.000384 \\
EPDM/TiC/POE (10/2/2) & 0.000426 \\
\hline
\end{tabular}


Table 7 Mechanical properties of EPDM/TiC composites

\begin{tabular}{ccccc}
\hline Sample & Hardness & $\begin{array}{c}\text { Tensile } \\
\text { strength } \\
\text { SPa }\end{array}$ & $\begin{array}{c}\text { Elongation at } \\
\text { break } \\
\%\end{array}$ & $\begin{array}{c}\text { Tear strength } \\
\mathrm{kN} / \mathrm{m}\end{array}$ \\
\hline EPDM control & 50 & $1.38 \pm 0.32$ & $162 \pm 21$ & $8.01 \pm 0.91$ \\
EPDM/unmodified TiC (10/1) & 54 & $1.43 \pm 0.10$ & $146 \pm 11$ & $8.86 \pm 1.46$ \\
EPDM/TiC $(10 / 1)$ & 56 & $3.51 \pm 0.22$ & $141 \pm 16$ & $12.61 \pm 0.89$ \\
EPDM/TiC $(10 / 2)$ & 63 & $4.63 \pm 0.04$ & $123 \pm 21$ & $13.57 \pm 1.28$ \\
EPDM/TiC/POE (10/2/1) & 66 & $6.36 \pm 0.12$ & $131 \pm 19$ & $15.78 \pm 1.08$ \\
EPDM/TiC/POE (10/2/2) & 69 & $8.33 \pm 0.34$ & $121 \pm 11$ & $18.80 \pm 1.22$ \\
\hline
\end{tabular}


Table 8 Surface and volume resistivity of EPDM/TiC composites

\begin{tabular}{ccc}
\hline Sample & Surface resistivity $(\Omega)$ & Volume resistivity $(\Omega \cdot \mathrm{m})$ \\
\hline EPDM & $5.0 \times 10^{12}$ & $1.5 \times 10^{15}$ \\
EPDM/unmodified TiC (10/1) & $1.5 \times 10^{12}$ & $1.3 \times 10^{13}$ \\
EPDM/TiC (10/1) & $5.9 \times 10^{11}$ & $6.8 \times 10^{12}$ \\
EPDM/TiC (10/2) & $3.7 \times 10^{11}$ & $4.7 \times 10^{12}$ \\
EPDM/TiC/POE $(10 / 2 / 1)$ & $2.4 \times 10^{11}$ & $3.9 \times 10^{12}$ \\
EPDM/TiC/POE $(10 / 2 / 2)$ & $1.3 \times 10^{11}$ & $1.7 \times 10^{12}$ \\
\hline
\end{tabular}


Table 9 Thermal conductivity of EPDM/TiC composites

\begin{tabular}{cc}
\hline Sample & Thermal conductivity, W/(m·K) \\
\hline EPDM control & 0.239 \\
EPDM/unmodified TiC (10/1) & 0.242 \\
EPDM/TiC (10/1) & 0.253 \\
EPDM/TiC (10/2) & 0.281 \\
EPDM/TiC/POE (10/2/1) & 0.334 \\
EPDM/TiC/POE (10/2/2) & 0.416 \\
\hline
\end{tabular}

